Article

\title{
Film Students' Attitude toward Open Educational Resources (OERs) for Film Studies in Greece
}

\author{
Elissavet Georgiadou ${ }^{1, *}$ and Ioannis Kolaxizis ${ }^{2}$ \\ 1 School of Journalism and Mass Communications, Aristotle University of Thessaloniki, \\ 54625 Thessaloniki, Greece \\ 2 School of Film Studies, Aristotle University of Thessaloniki, 54124 Thessaloniki, Greece \\ * Correspondence: egeorgiadou@jour.auth.gr
}

Received: 29 May 2019; Accepted: 19 July 2019; Published: 24 July 2019

\begin{abstract}
Open Educational Resources (OERs) have become a very useful medium in the fields of education, research, and training in recent decades, supported by governments and highly respected universities and institutions worldwide. Today's university students-in western societies mainly-have been born and raised in a digital world; consuming, providing, and sharing information over the internet 24/7. In that respect, it is interesting to examine whether OERs are a type/kind of information that they would like to "consume, provide, and share" throughout their studies in a formal university course. The paper focus on the attitude toward OERs of students enrolled in a film studies course, offered by the Aristotle University of Thessaloniki, Greece. The aim of the study is to provide film educators with evidence regarding their students' attitudes toward OERs that can be useful in designing teaching strategies to enhance the learning process. Findings suggest that film students want to use OERs in their studies but many of them are not aware that these resources exist and that they are offered from highly recognized institutions and universities worldwide. Therefore, university teachers should assist students to develop familiarity with OERs of high quality and educational value as a useful aid to their studies.
\end{abstract}

Keywords: open educational resources (OERs); film studies; OER in Greece; higher education

\section{Introduction}

The proliferation and penetration of the internet in every aspect of human life in recent decades formed a global movement toward open knowledge. Within this context Open Educational Resources (OERs) have become a very useful medium in the fields of education, research, and training in all academic disciplines. Many researchers are focusing on OERS as a catalyst for innovation [1] and are also investigating the acceptance and usability of OERs in education [2-4]. To a much lesser degree, the students' point of view is investigated. However, this issue is equally important, as the vast majority of today's university students-in western societies mainly-have been born and raised in a digital world; consuming, providing, and sharing information over the internet all day long. In that respect, it is interesting to examine whether students are aware of such educational resources and whether OER is a type/kind of information that students would like to "consume, provide, and share" during their studies in a formal university course. More specifically, the research focus on students enrolled in the film studies course, offered by the Aristotle University of Thessaloniki, in Greece. The aim of the study is to provide film educators with evidence regarding their students' attitudes toward OERs that can be useful in designing teaching intervention strategies that enhance learning in higher education.

The paper first reviews the role of Open Educational Resources (OERs) in learning, focusing on definition, types of OERs and where they can be found, challenges associated with OERs and evaluation issues, awareness of OERs, and OERs for film studies. Next, it presents the research on 
film students' attitude toward Open Educational Resources in Greece: Data collection and research instruments and data analysis; and finally, it provides the conclusion and discussion on the current study and suggestions for further research.

\section{The Role of Open Educational Resources (OERs) in Learning}

The term Open Educational Resources (OERs) was coined at UNESCO's 2002 Forum on Open Courseware. The term designates "teaching, learning, and research materials in any medium, digital or otherwise, that reside in the public domain or have been released under an open license that permits no-cost access, use, adaptation, and redistribution by others with no or limited restrictions. Open licensing is built within the existing framework of intellectual property rights as defined by relevant international conventions and respects the authorship of the work" [5].

Open Educational Resources (OERs) help improve education across the globe. They are important for both developing countries, where access to educational practices and materials may be limited, and wealthy industrialized countries, as they can offer significant cost savings. Students can benefit as OERs offer free access to some of the world's best courses and even degree programs and huge cost savings as alternatives to expensive textbooks. Teachers, ministries of education, and governments can benefit as OERs provide free and legal access to some of the world's best courses. Educators can then adapt them to local languages and cultures and use them as a basis for innovation. Finally, people of all ages and backgrounds can benefit as free information is a fundamental human right, and OERs make it possible for people of all ages and backgrounds to learn more about the world around them and access the tools they need to improve their lives and livelihoods [6].

There is much research on the field of OER from countries, educational organizations and institutions. The World OER Congress held at UNESCO, Paris on 20-22 June 2012, taking into account relevant international statements such as The Universal Declaration of Human Rights (Article 26.1), which states that: "Everyone has the right to education"; The International Covenant on Economic, Social, and Cultural Rights (Article 13.1), which recognizes "the right of everyone to education", and also existing Declarations and Guidelines on Open Educational Resources, recommends that States, within their capacities and authority should: (a) Foster awareness and use of OER, (b) facilitate enabling environments for use of Information and Communications Technologies (ICT), (c) reinforce the development of strategies and policies on OER, (d) promote the understanding and use of open licensing frameworks, (e) support capacity building for the sustainable development of quality learning materials, (f) foster strategic alliances for OER, (g) encourage the development and adaptation of OER in a variety of languages and cultural contexts, (h) encourage research on OER, (i) facilitate finding, retrieving, and sharing of OER, (j) encourage the open licensing of educational materials produced with public funds [7].

Moreover, the second World Open Educational Resources (OER) Congress that took place from 18 to 20 September 2017 in Ljubljana, Slovenia, organized by UNESCO and the Government of Slovenia/Ministry of Education, Science and Sport, resulted in the "Ljubljana OER Action Plan" that provides recommendations to stakeholders-identified as educators, teacher trainers, librarians, learners, parents, educational policy makers at both the governmental and institutional level, teachers, and other-in five strategic areas: Building the capacity of users to find, re-use, create and share OERs; language and cultural issues; ensuring inclusive and equitable access to quality OERs; developing sustainability models; and developing supportive policy environments [8].

In conclusion, OERs allow users to engage with the 5R activities [9]: Retain, Reuse, Revise, Remix and Redistribute.

\subsection{Types of OERs and Where They Can Be Found}

Open Educational Resources (OERs) can be divided in many ways. Open courseware (OCW), open textbooks and Massive Online Open Courses (MOOCs) can all be. Examples of OERs include complete courses, individual course units or modules, textbooks, lesson plans, syllabi, lectures, 
assignments, game-based learning programs, quizzes, podcasts videos, audios, interactive simulations, and interactive multimedia. OERs can also be divided up by their content format, though most OERs will be composed of a variety of media: Text-led, video-led, animation-led, and multiple media [10]. Anyone with internet access can use OERs that are usually not dependent on location or membership of an institution. Most OERs use Creative Commons (CC) Licenses to ensure that materials can be used in a wide variety of ways, e.g., edited, remixed, enhanced, copied, or redistributed.

Moreover, OERs can be 'big' or 'little'. 'Big' OERs are large-scale, funded OER projects such as MIT's Open Courseware, Open University's OpenLearn, Coursera MOOCs that are usually of high quality, contain explicit teaching aims, presented in a uniform style and form part of a time-limited, focused project with a portal and associated research and data. On the other hand, 'little' OERs are low-cost resources, individually produced by anyone, not just educators. They might not have explicit educational aims, have low production quality and are shared through a range of third-party sites and services $[11,12]$.

There is no single comprehensive listing of all available OERs, as their scope and availability is ever expanding. There are several different repositories and websites where open education resources can be found. OER Commons (https://www.oercommons.org/), Open Education Consortium (https://www.oeconsortium.org/), EDSITEment!: The Best of the Humanities on the Web (https:// edsitement.neh.gov/), Open Professionals Education Network (https://open4us.org/find-oer/), Teaching Commons (https://teachingcommons.us/), and Future Learn (https://www.futurelearn.com/) are just some examples. Most of them provide advanced search options to different OER source types. For example, the Openly Available Sources Integrated Search (OASIS) project (https://oasis.geneseo.edu/) allows users to search textbooks, courses, source materials, interactive simulations, public domain books, audiobooks, modules, open access books, videos, podcasts, learning objects, and primary sources. Additionally, there are specialized content sites, that offer resources under CC licenses only in one format of content, such as video (e.g., YouTube, Vimeo). Moreover, open educational resources can be found in most universities' sites around the world. Excellent examples are given by Open University, UK http://openlearn.open.ac.uk, Massachusetts Institute of Technology http://ocw.mit.edu and Coursera, founded by Stanford University https://www.coursera.org/. Thousands of OER sources return search results via Creative Commons and Google Advanced Search for web pages according to usage rights. Other useful references are a comprehensive listing of OER sources and sites on the Internet, http://www.OERSources.com/, which is updated regularly by Marcus P. Zillman [13], Executive Director of Virtual Private Library, and an updated list of OER search engines published by San Jacindo College Library [14].

\subsection{Challenges Associated with OERs and Evaluation Issues}

There are specific challenges associated with OERs besides language, which is a key issue, as the vast majority of OERs are available only in English language. The International Federation of Libraries Association summarize the most important as follows [15]:

(a) Legal reasons: Understanding of licensing terms is required, which may stand in the way of particular types of reuse, such as newspaper articles or pictures.

(b) Legal issues for platforms hosting OER: In some circumstances, they may be made liable for the actions of uploaders.

(c) Privacy issues: Users may need to be aware that the use of some OER may involve data collection.

(d) Level of legal and copyright literacy of developers, librarians, and others: Where this is not clear, there may be mistakes or confusion as to what is possible.

(e) A need to combat the assumption that an OER is of a lower quality than conventional materials and sources, given that it does not always follow a traditional editorial process. OERs can be peer reviewed through open methods and there is a lot of high-quality material available. 
(f) Teachers and other educators creating OERs do not receive credit for the time invested, in contrast with traditional educational sources, such as textbooks.

(g) Discoverability: While a lot of OERs exist, they may not easily be found by teachers or learners.

(h) Technological barriers: ICTs are not accessible to everyone, and many lacks the skills or confidence to use them. With a large amount of OER material made available online, efforts need to be made both in digital literacy and access to digital technologies.

(i) Accessibility issues: Not adapting materials to the needs of users with disabilities can stand in the way of access to knowledge.

The challenges of technological barriers and-to a great extent-accessibility are also associated with digital divide issues and can be addressed only within global and governmental initiatives and policies. However, there are ways of evaluating existing OERs in terms of their usefulness in the educational process. Numerous studies focus on this issue that often results in guidelines, checklists, and rubrics, e.g., [16-19], that address several criteria, including:

(a) Quality peer review: Reputation of authors and/or institution,

(b) appropriateness of content: Content is accurate and fully cited, learning level and source learning objectives are explicit,

(c) technical issues and production quality: High readability of content; clear and understandable information; easy-to-navigate interface,

(d) accessibility: Availability of resources in different format; adaptability and modularity,

(e) interactivity: Active learning; class participation; formative and summative evaluation of learning,

(f) supplementary resources: Links to other types and formats of OERs relevant to the subject, and

(g) licensing to reuse, modify, and share.

These criteria can be adapted accordingly to different types and formats of OERs. More effort is required to evaluate an open courseware than an open textbook.

\subsection{OER Awareness}

OERs are beneficial to students as several studies suggest. Qualitative and quantitative data published that examine students' perceptions of OERs in place of standard resources shown that OERs are improving students' attitudes and behaviors toward learning [20-24]. However, an important problem in the proliferation of OERs in education is awareness. Survey results from over 3000 higher education faculty in the US show that most faculty remain unaware of open educational resources (OERs), and it is not a driving force in educational material adoption decisions. Important barriers are the effort required to find and evaluate the educational materials [25].

Further, students are not aware of OERs as studies suggest. Hurt, exploring students' perceptions of OERs in a life science faculty at the De Monforte University, UK, found that most of the students had not heard the term OER [26]. Similarly, Onaifo in his investigation on students' awareness and attitudes toward OERs at the University of Lagos in Nigeria concluded that participants were limited in their understanding of the concept of OERs as well as in their awareness of OER repositories [27]. Gruszczynska from Sheffield Hallam University, who investigated students' awareness towards OERs, suggests that it is important to spend time exploring student perceptions and attitudes toward OERs in addition to equipping them with the relevant technical skills [28].

The research findings in this field triggered our interest to investigate film students' attitude toward OERs for film studies in Greece, which is a small country. As Kurelovic suggests [29], "the implementation of OER has certain limitations, in particular for small countries which use a non-English language, have limited resources and support to customize and create OER, their educational practice is founded on traditional teaching methods with occasional use of digital contents and ICT. The awareness raising and positive attitudes about OER are the first important step toward its acceptance". 


\subsection{OERs for Film Studies}

Film studies is an academic discipline that deals with a combination of theoretical, historical, critical, and technical approaches to films. Educational institutions/universities worldwide offer undergraduate and postgraduate courses on this discipline that usually address the whole or part of these approaches, aiming to provide both theoretical and technical skills to students who wish to pursue a career as filmmakers or film theorists.

There are many OERs that focus on film studies offering different types and forms of educational material that can enhance the learning process of students in this discipline. Since the focus of attention in this study is undergraduate university students, the issue of reputation of authors and/or institutions regarding OERs is of a high priority in suggesting sources that can effectively complement the university curriculum. In that respect, a search performed on 25 May 2019 using the keyword "film" in OER Commons portal (www.oercommons.org/) returned 734 results. Of these, 334 were aimed at higher education students and included courseware from recognized universities and institutes (e.g., UK Open University, MIT, U.C. Berkeley, University of Nottingham, Harvard University, The British Film Institute (BFI), and UK National Film and Television School). 192 of these are included in MIT Open Courseware repository (ocw.mit.edu) that return 4.550 items in total under the keyword "film". Most of these courses consisted of syllabus, films and readings, lecture and lab videos, assignments and projects, related resources, and an option to download course materials in the form of a package that contains the same content as the online version of the courses. Moreover, searching under the same keyword in the OASIS OER repository (https://oasis.geneseo.edu) returned 505 results on course material related to film that include open access book (282), video (97), primary source (41), module (36), public domain book (21), course (20), course material (5), and public domain audiobook (3). Moreover 488 courses in the form of an interactive textbook, featuring pre-recorded videos, quizzes, and projects associated with film exist in the Coursera repository (https://www.coursera.org/).

There are also a few OERs for film studies in Greek language found in the National Repository of Greek academic open courses (opencourses.gr), developed with the aim of supporting the open digital courses offered by higher education institutes all over Greece.

As mentioned in Section 2.1, there are many ways to locate OERs for film studies. The above mentioned are indicative and there are more to explore in a further study that will address the issue of available OERs for film studies.

\section{Research: Film Students' Attitude toward OERs for Film Studies in Greece}

Despite the large number of available OERs in film studies, there is no research evidence that students in higher education film studies in Greece are aware of these educational resources. In addition, their intention to use them and also to support them with resources has not been investigated.

This study will therefore address the following research questions (RQs):

RQ1. To what degree are students of higher education film studies in Greece aware of OERs and their potential usefulness for their academic discipline?

RQ2. Do film students intend to use OERs as additional educational resources in their studies at the university?

RQ3. Do film students intend to contribute to OER repositories with their own peer-reviewed work?

The study was conducted at the School of Film Studies of the Aristotle University, the only public higher-education film school in Greece, established in 2004 in Thessaloniki, Greece. It offers a five-year program of studies, covering both the first and second cycle, leading to a degree in eight possible directions: Screenwriting, film directing, cinematography, film editing, sound and music of cinema, production management, set and costume design, and film theory and history. 


\subsection{Research Methodology}

\subsubsection{Data Collection and Research Instrument}

Data for the study was collected during May of the 2018-2019 academic year. This month, that is the last month of the spring semester, was chosen to conduct the research as even first year students acquired internet search skills through their research in term papers and minor and major projects.

The research instrument was a brief questionnaire - in an electronic form — consisting of twelve close-ended items that ask respondents to choose from a distinct set of pre-defined responses ("yes/no/I do not know" or among a set of multiple choices) in order to gather quantitative data from respondents.

The design of the research instrument and the formulation of the items considered the challenges and the evaluation issues associated with OERs, as presented in Section 2.2. A pilot study was conducted prior to mass distribution, to identify and edit its overall design and content.

The decision to keep the research instrument brief, with closed-ended items mostly, was based on our intention to focus only on the research questions, since the presented study is an initial research effort in investigating film students' attitude toward OERs for film studies in Greece, expecting that the collected data will raise further research questions that will be addressed in the future.

The questionnaire presented in Appendix A opened with a brief description/definition of OERs as follows: "Open Educational Resources (OERs) are educational materials distributed under a Creative Commons license that allow free access and use at no cost. In addition, OERs can be updated, translated, completed, and then distributed by users without limitations. OERs can take many forms, such as books, activities, video lectures, audio lectures, films, evaluation tests, etc. They can also have the form of a complete courseware that includes video lectures, discussion, commentary, evaluation, additional resources, and more". In addition to demographic items, the questionnaire was structured in three parts: The first part included items Q1-Q7 that investigate the awareness and intention to use OERs in film studies; the second part (Q8-Q11) focused on the form/types of OERs in film studies and how to locate and evaluate them; and the third part (Q12) investigated the intention of film students to support film OER repositories with their own peer-reviewed work. Finally, an open-ended item (Q13) was used to record additional issues on the research topic and specific OERs used by students in film studies.

\subsubsection{Data Analysis}

The questionnaire was completed and returned by 136 students. Descriptive statistics were used to analyze the quantitative data obtained. This approach was chosen as the study has a specific purpose that is investigating a phenomenon in an initial phase. Therefore, summaries about the sample and the measures can address the research questions. The students completed and returned the questionnaire, distributed almost evenly across the five years of the course and the two genres (male $48 \%$, female $52 \%$ ). Therefore, no associations regarding the demographics could provide findings and hence it was not performed, despite our initial intention.

\section{Part 1: Awareness and potential usefulness of OERs in film studies}

Fifty-six percent of the sample stated that they are aware about OERs for their discipline and they used them in their studies (Figure 1). The remaining 44\% stressed that they did not know that OERs exist for film studies; however, they stated their interest in using them in the future as an aid to their studies.

A majority of the students who participated in the study (94\%) found OERs useful for higher education film students (Figure 2) and also people interested in terms of lifelong learning.

In addition, 70\% did not know that the UK Open University, the Massachusetts Institute of Technology, and other universities and institutions around the world provide free courseware on a variety of film-related subjects (Figure 3). 
Do you know that you can find many OERs

for film studies on the Internet?

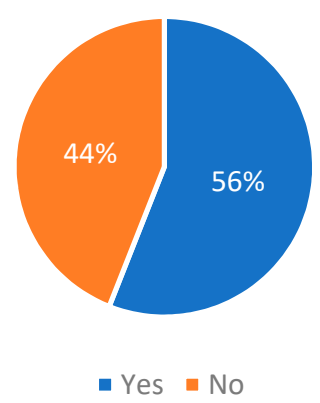

Figure 1. Responses on $\mathrm{Q} 1$ of the questionnaire

How useful do you think are OERs to people studying film in a higher education institution?

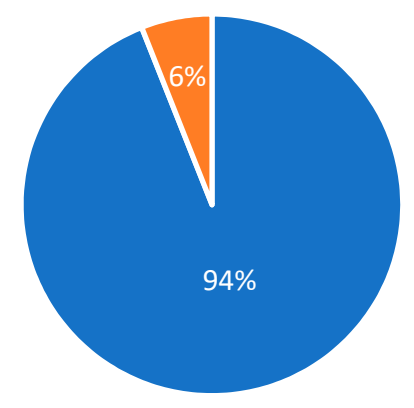

- Very useful - Not useful at all

Figure 2. Responses on $\mathrm{Q} 3$ of the questionnaire

Do you know that the UK Open University, the Massachusetts Institute of Technology, and other universities and institutions around the world provide free courseware on a variety of film-related subjects?

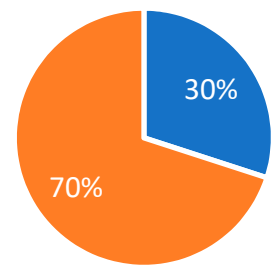

- Yes a No

Figure 3. Responses on $\mathrm{Q} 5$ of the questionnaire

The students who participated in the study stated that they would be more interested in using OERs on film history and theory $(75 \%)$ and to a lesser degree (25\%) OERs on other film fields such as screenwriting, film directing, cinematography, film editing, sound and music of cinema, production management, set and costume design, and film pedagogy. Moreover, 97\% would like to have access to 
a portal with OERs for film studies categorized by area of interest (Figure 4), and they would mostly prefer to access this portal from their PC (75\%) and their mobile phone (25\%).

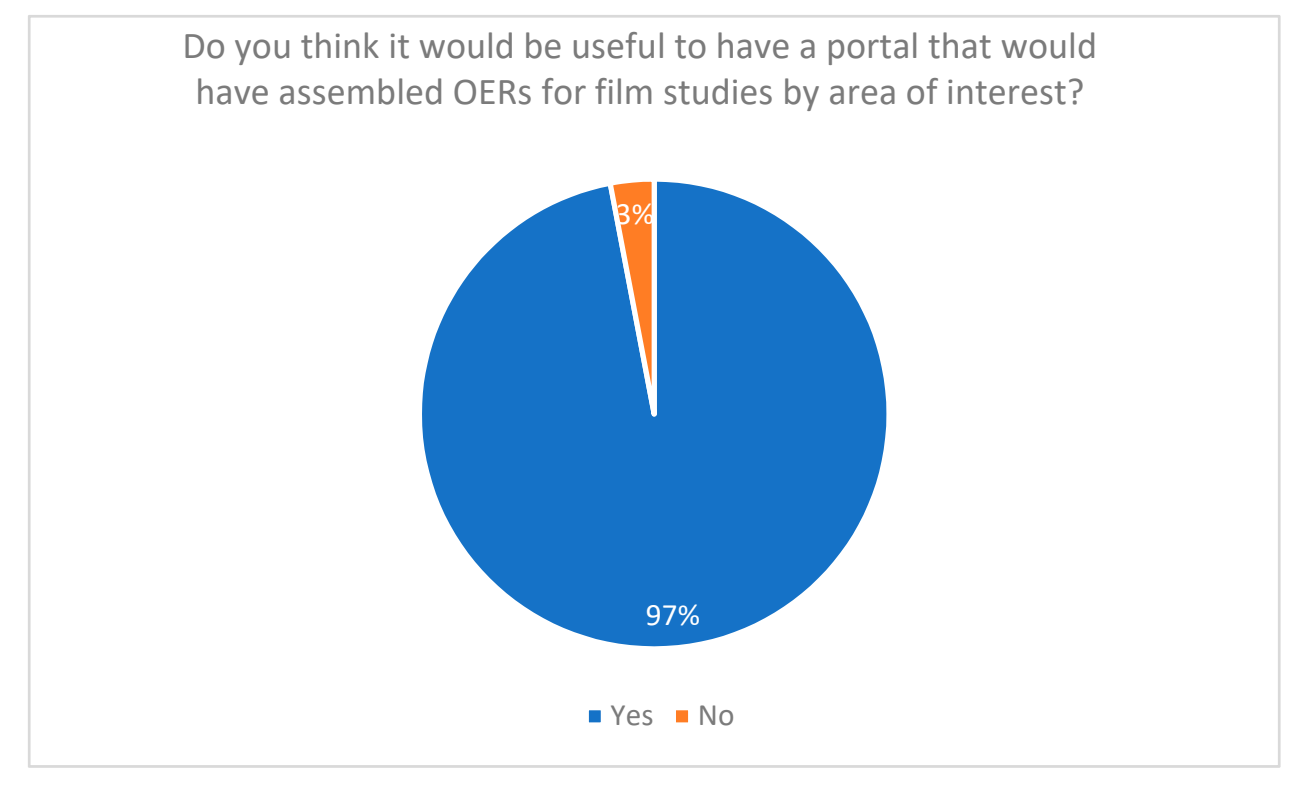

Figure 4. Responses on Q7 of the questionnaire

\section{Part 2: Form/types of OERs in film studies-locating and evaluating}

Regarding the form and type of OERs used during their studies, students stated that they used mostly e-books, films from various free access archives, and tutorials for image-, audio-, and video-editing software. They used, to a lesser degree, video and audio lectures and complete courseware. They usually find the resources using a general-purpose search engine $(65 \%)$ and/or by following their professors' suggestions (20\%). Only 15\% stated that they use search engines for open educational resource platforms and no one stated that they locate OERs through university sites that offer open courses (Figure 5). It must be noted that the percentage in this set of items refers only to students that stated in Part 2 that they used OERs, that is, $56 \%$ of the sample.

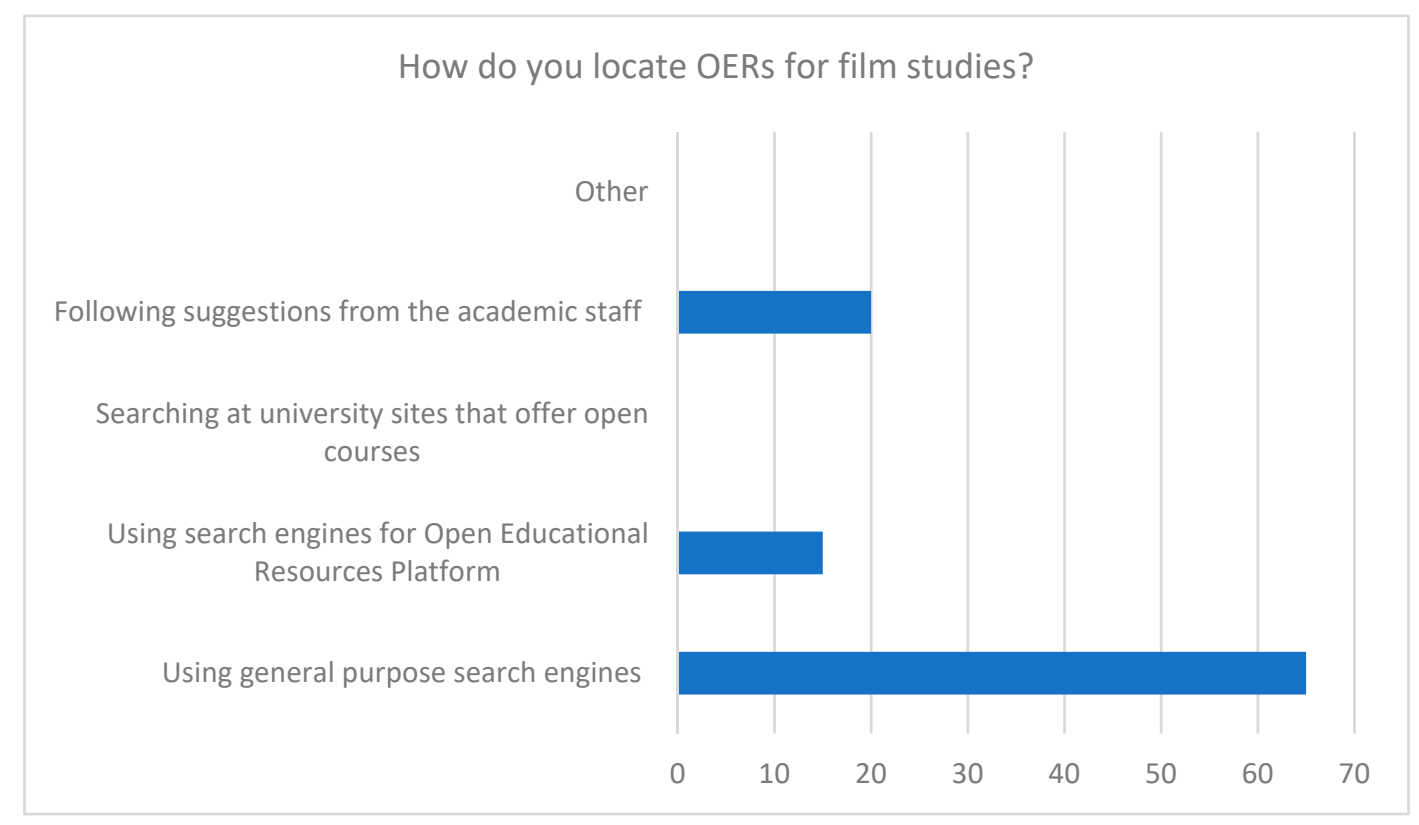

Figure 5. Responses on Q9 of the questionnaire (56\% of the sample) 
Students consider as the most important issues-top to down-associated with OERs (Figure 6): The quality and validity of the information they contain (91\%), locating open educational resources for film studies $(88 \%)$, personal security issues, as their use may require the collection of personal data $(80 \%)$, the language of most OERs is English and presentation of the information in other forms $(67 \%)$, and copyright issues of the information they contain (52\%).

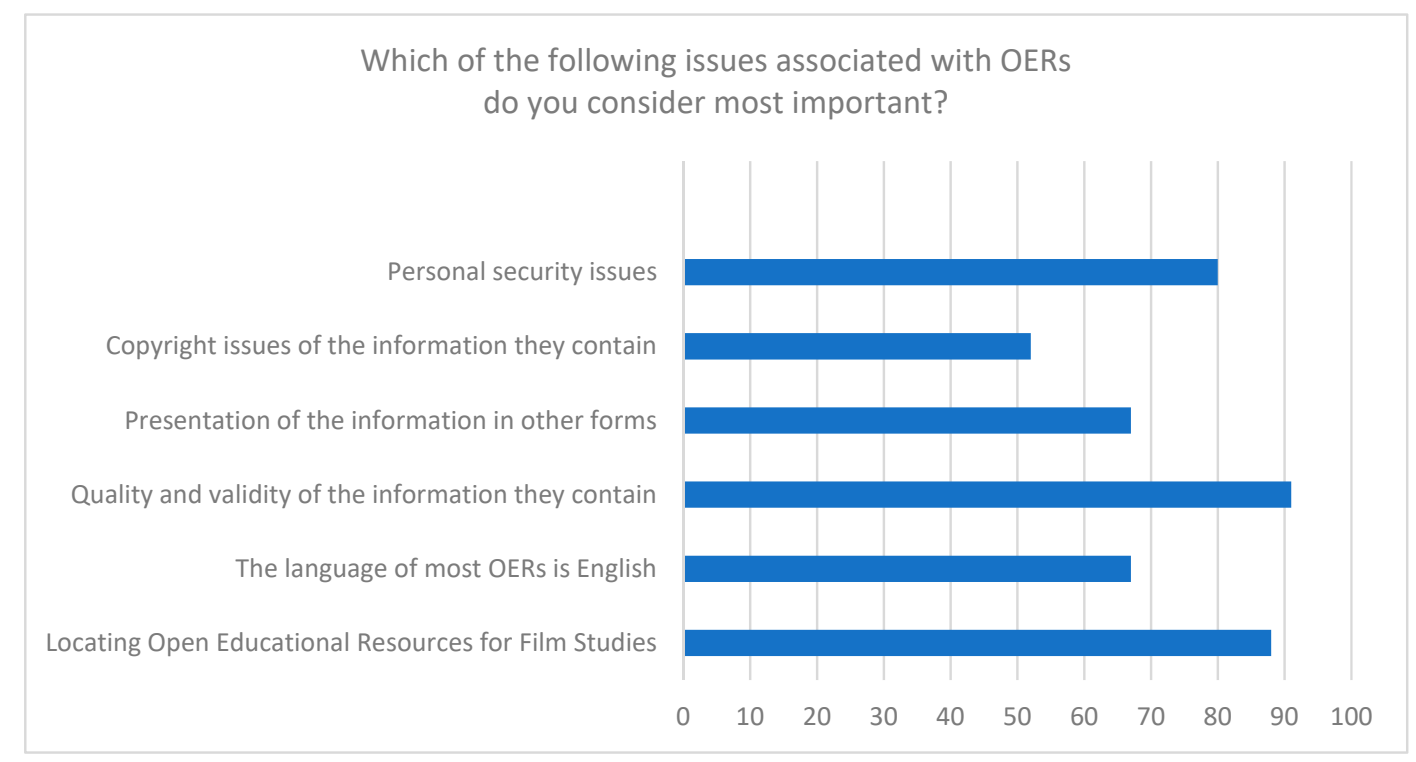

Figure 6. Responses on $\mathrm{Q} 10$ of the questionnaire

In addition, students choose whether to use or not use an OER-top to down-considering the following criteria (Figure 7): OERs include additional sources for the subject they examine (85\%), validity/credibility, i.e., offered by a highly recognized educational institution (75\%), good quality of content, i.e., text, image, video, audio, or animation $(70 \%)$, clearly presented content that addresses the educational objectives of the course at the university $(67 \%)$, and interactive content $(37 \%)$.

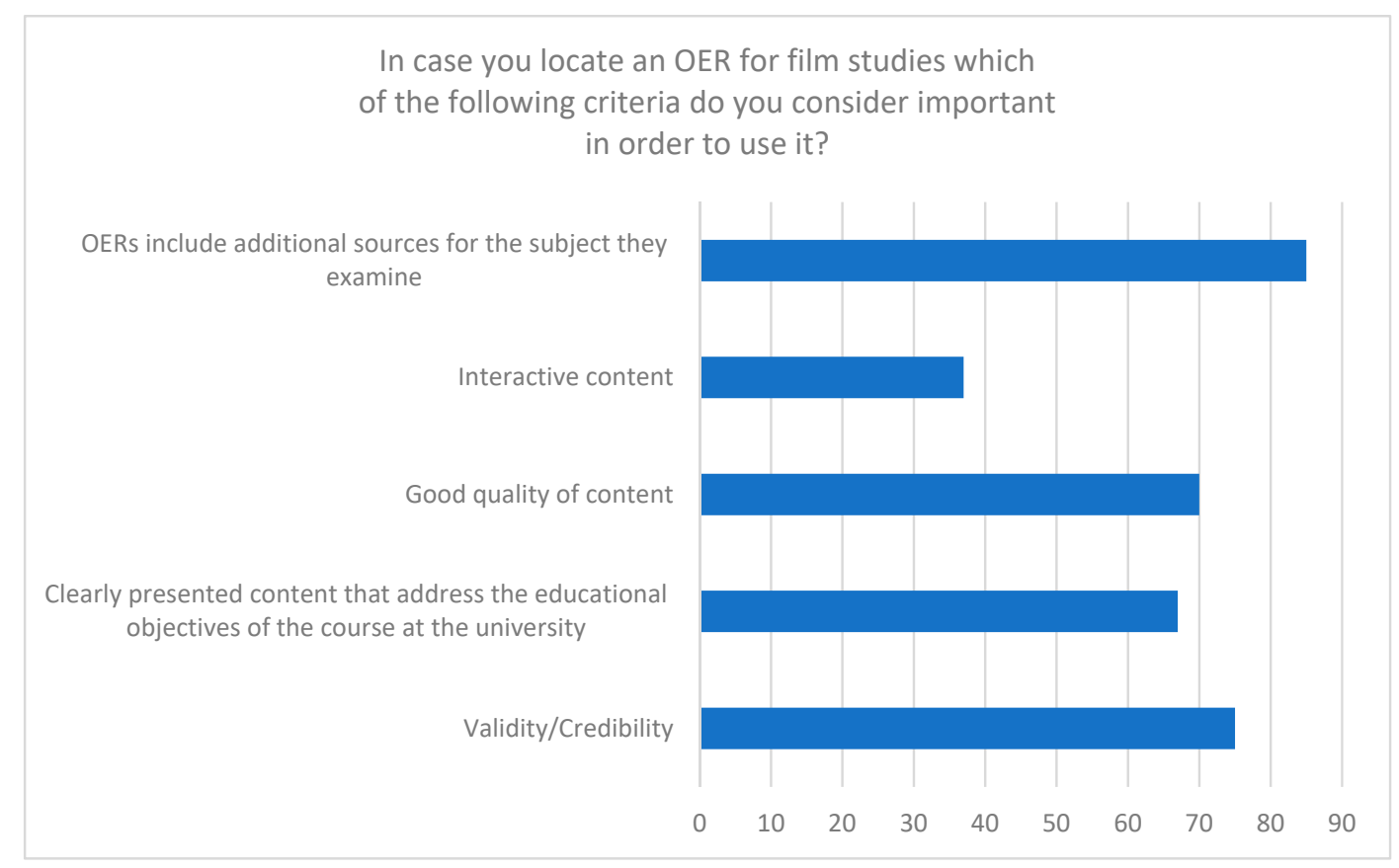

Figure 7. Responses on Q11 of the questionnaire 


\section{Part 3: Intention of creating OERs for film studies}

Eighty-eight percent of the participants stated that they intend to make available as OERs learning objects produced by them during their studies, such as a written or audiovisual work (Figure 8).

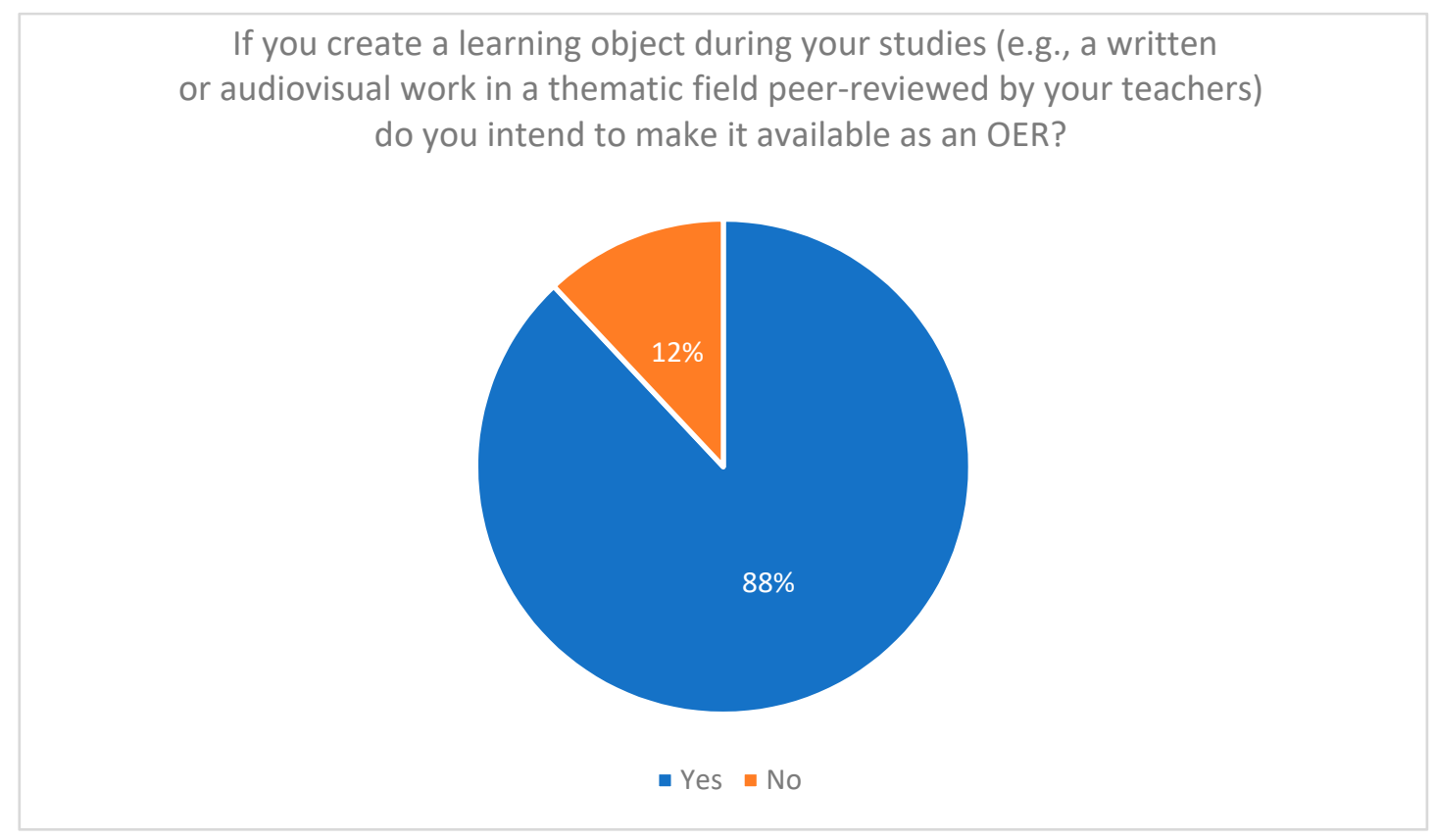

Figure 8. Responses on $\mathrm{Q} 12$ of the questionnaire

The remaining $12 \%$ would not do so as they want to keep the copyright and/or believe that a student's work cannot be a learning object. However, none of them stated that they do not believe in free access to knowledge.

Finally, limited participation was recorded in the open-ended item. Only six students noted that they used Coursera MOOCs, YouTube Open Courses, MIT OCW, and Mathesis that is dedicated to MOOCs in Greek.

\section{Conclusions}

The present study has tried to provide some initial findings on film students' attitude toward OERs as a medium to enhance their learning in the film studies course at the Aristotle University of Thessaloniki, Greece, that can be used by university teachers in the process of developing teaching strategies that can enhance the learning process. The analysis of the data collected from the research instrument provides answers to the research questions as follows. Film students want to use OERs in their studies, but many of them are not aware that these resources exist and are offered from highly recognized institutions and universities worldwide. Almost all the participants stated that would like to have access from their PC to a portal with OERs for film studies categorized by area of interest, and they are mostly interested in OERs on film history and theory and to a lesser degree in other film fields. Most participants—-from those that stated they used OERs in their studies-mostly used OERs in form of e-books, films from various free access archives, and tutorials for image-, audio-, and videoediting software and, to a much lesser degree, video and audio lectures and open courseware. They usually found the resources using a general-purpose search engine and/or by following their professors' suggestions. Students considered quality and validity, discoverability, and personal security as the most important issues associated with OERs. Moreover, they believed that their preference to use an OER is based mostly on the additional sources it provides, on its clarity in terms of educational objectives and quality of content, and on whether it is offered by a highly recognized educational 
institution. Students cared less for interactive content. Finally, most of the participants wanted to contribute to the open knowledge movement with their own peer-reviewed work.

The findings suggest that university teachers in film studies in Greece should consider teaching strategies that promote the use of quality and peer-reviewed OERs for their students. The strategies should include acts toward informing the students about the importance of OERs of different forms and types in film studies, where and how to locate them, and how to evaluate and use them as additional educational resources within the university course.

The present research addressed an issue in its initial phase, as there is no published evidence on the attitude of film study students or film educators toward OERs in Greece. However, several issues need further research, such as examining the film educators' point of view on the research issue, designing strategies for technology-enhanced learning that have OERs as their basis, developing a framework for presenting OERs for film studies gathered in a single place. Finally, it must be noted that results of the study presented in this paper derive from a random sample representing a certain population (almost the $1 / 5$ of students enrolled in the film course), and they cannot be easily generalized for the population it represented, i.e., all the film students at the Aristotle University in Thessaloniki, Greece. A bigger sample may give different results.

\section{Discussion}

Educators and students around the world have begun to acknowledge the importance of OERs in educational practice; yet there is a need for more direction about the role that OERs will play in learning in the future. The present study suggests that the majority of the participants are positive about many aspects of OERs and they are willing to contribute to the open education movement with their own peer-reviewed work, although almost half of the them were unaware of OERs. The findings agree with what the University of the People [30] the world's first non-profit, tuition-free, accredited, online, American university argues, based on the Babson Survey Research Group findings (see [25]): That lack of awareness is the biggest obstacle for Open Educational Resources. "OER could play a role in democratizing the way we impart knowledge and education to students, but this will never happen until we address the central issue revealed by the Babson Survey Research Group-which is the simple, yet humongous, issue of awareness" [30].

Author Contributions: Investigation, E.G.; Methodology, E.G. and I.K.; Writing-original draft, E.G.; Writing-review \& editing, E.G. and I.K.

Funding: This research received no external funding.

Acknowledgments: The authors gratefully acknowledge the valuable input of film students that participated in the study.

Conflicts of Interest: The authors declare no conflict of interest.

\section{Appendix A -Questionnaire Items}

\section{Part 1: Q1-Q7 Awareness and intention to use OERs in film studies}

Q1. Do you know that you can find many OERs for film studies on the Internet?

Yes No

Q2. Have you used OERs as an aid to your studies?

Yes No

If no, would you be interested in using them in the future?

Yes No

Q3. How useful do you think are OERs to people studying film in a higher education institution?

- Very useful

- Not useful at all

- I do not know 
Q4. Do you believe that OERS are useful not only for people who are studying film in higher education but also for those interested in lifelong learning?

- Yes

- No

- I do not know

Q5. Do you know that the UK Open University, the Massachusetts Institute of Technology and other universities and institutions around the world provide free courseware on a variety of film-related subjects?

Yes No

Q6. In which area of film studies do you think OERs are more useful?

- Screenwriting

- Film directing

- Cinematography

- $\quad$ Film editing

- Sound and music of cinema

- Production management

- Set and costume design

- Film theory

- Film history

- Film pedagogy

- $\quad$ All the above

Q7. Do you think it would be useful to have a portal that would have assembled OERs for film studies by area of interest?

Yes No

If so, how would you prefer to have access to it?

- Desktop computer

- Tablet

- Mobile phone

- $\quad$ All the above

Part 2: Q8-Q11 Form/types of OERs in film studies-locating and evaluating

Q8. In case you used OERs during your studies (answer Yes in Q2), which is the form/type they had?

- E-books

- Films from various free access archives

- Video lectures

- Audio lectures

- Tutorials for image, audio, and video editing software

- Complete courseware that includes instructional guides, video lectures, discussion, commentary, evaluation, additional resources

- Other

Q9. How do you locate OERs for film studies?

- Using general purpose search engines 
- Using search engines for Open Educational Resources Platforms (e.g., https://www.oercommons. org/), Open Professionals Education Network (https://open4us.org/find-oer/), Teaching Commons (https://teachingcommons.us/)

- Searching at university sites that offer open courses (e.g., MIT Open Courseware, UK Open University)

- Following suggestions from the academic staff

- Other

Q10. Which of the following issues associated with OERs do you consider most important?

- Locating Open Educational Resources for film studies

- The language of most OERs is English

- Quality and validity of the information they contain

- Presentation of the information in other forms (e.g., a video is also available in text)

- Copyright issues of the information they contain

- Personal security issues, as their use may require the collection of personal data

Q11. In case you locate an OER for film studies, which of the following criteria you consider important in order to use it?

- Validity/credibility (e.g., offered by a highly recognized educational institution such as Open University, UK or the Massachusetts Institute of Technology)

- Clearly presented content that addresses the educational objectives of the course at the university

- Good quality of content (text, image, video, audio, animation, etc.)

- Interactive content

- OERs include additional sources for the subject they examine (e.g., links to relevant lessons or books)

Part 3: Intention of film students to support film OER repositories with their own peer-reviewed work

Q12. If you create a learning object during your studies (e.g., a written or audiovisual work in a thematic field peer-reviewed by your teachers) do you intend to make it available as an OER?

Yes No

If not for what reasons?

- I want to keep the copyright for myself

- I do not think that a student's work can be a learning object

- I do not believe in free access to knowledge

Q13. Fill in the titles from open sources you may have used during your studies and any comments you might have about OERs in film studies.

\section{References}

1. Orr, D.; Rimini, M.; Damme, D. Open Educational Resources: A Catalyst for Innovation; Educational Research and Innovation, OECD Publishing: Paris, France, 2015. [CrossRef]

2. Padhi, N. Acceptance and Usability of OER in India: An Investigation Using UTAUT Model. Open Praxis 2018, 10, 55-65. [CrossRef]

3. Mtebe, J.S.; Raisamo, R. Challenges and Instructors' Intention to Adopt and Use Open Educational Resources in Higher Education in Tanzania. Int. Rev. Open Dist. Learn. 2014, 15, 249-271. Available online: https://files.eric.ed.gov/fulltext/EJ1024358.pdf (accessed on 10 May 2019). 
4. Hayman, J. Open is an Invitation: Exploring Use of Open Educational Resources with Ontario Post-Secondary Educators. Unpublished Ph.D. Thesis, Arizona State University, Tempe, AZ, USA, 2018. Available online: http://jennihayman.com/wp-content/uploads/2018/12/Dissertation_Hayman_ December2018_OpenlyPublished.pdf (accessed on 10 May 2019).

5. Unesco. UNESCO promotes new initiative for free educational resources on the Internet. 2002. Available online: http://www.unesco.org/education/news_en/080702_free_edu_ress.shtml (accessed on 10 May 2019).

6. Unesco. Open Educational Resources (OER). Available online: https://en.unesco.org/themes/buildingknowledge-societies/oer (accessed on 10 May 2019).

7. Unesco. OER Declaration. 2012. Available online: https://unesdoc.unesco.org/ark:/48223/pf0000246687 (accessed on 10 May 2019).

8. Unesco. Second World OER Congress Ljubljana OER Action Plan. 2017. Available online: https://en.unesco. org/sites/default/files/ljubljana_oer_action_plan_pdf (accessed on 10 May 2019).

9. Wiley, D. Defining the "Open" in Open Content and Open Educational Resources. Available online: https://opencontent.org/definition/ (accessed on 10 May 2019).

10. Open Education Policy Network. Open Education Handbook. Available online: https://oerpolicy.eu/wpcontent/uploads/sites/4/2017/07/Open-Education-Handbook.pdf (accessed on 10 May 2019).

11. Hoyle, M. OER and a Pedagogy of Abundance. 2009. Available online: http://einiverse.eingang.org/2009/11/ 18/oer-and-a-pedagogy-of-abundance/\#more-181 (accessed on 10 May 2019).

12. Weller, M. Big and little OER. In Proceedings of the Open ED 2010 Seventh Annual Open Education Conference, Barcelona, Spain, 2-4 November 2010.

13. Zillman, M.P. Open Educational Resources (OER) Sources. 2019. Available online: http://whitepapers. virtualprivatelibrary.net/OER_Sources.pdf (accessed on 10 May 2019).

14. San Jacindo College Library. Open Educational Resources: OER Search Engines. n.d. Available online: https://sjcd.libguides.com/c.php?g=534967\&p=3659854 (accessed on 10 May 2019).

15. IFLA. Open Educational Resources and Libraries a Briefing. Available online: https://www.ifla.org/files/ assets/clm/news/oer_ifla_brief.pdf (accessed on 10 May 2019).

16. Achieve n.d. Achieve OER Rubrics. Available online: https://www.achieve.org/publications/achieve-oerrubrics (accessed on 10 May 2019).

17. Pierce College n.d. The Pop Rubric. Available online: https://piercemil.instructure.com/courses/1264001/ pages/professional-development (accessed on 10 May 2019).

18. Affordable Learning Georgia. Affordable Learning Georgia OER Evaluation Criteria. n.d. Available online: https://www.affordablelearninggeorgia.org/documents/R4_criteria.pdf (accessed on 10 May 2019).

19. BC campus. BC campus Textbook Review Criteria. n.d. Available online: https://open.bccampus.ca/bc-opentextbooks-review-criteria/ (accessed on 10 May 2019).

20. Fischer, L.; Hilton, J.; Robinson, T.J.; Wiley, D. A Multi-institutional study of the impact of open textbook adoption on the learning outcomes of post-secondary students. J. Comput. High. Edu. 2015, 27, 159-172. [CrossRef]

21. Bowen, W.; Chingos, M.; Lack, K.; Nygren, T. Interactive learning online at public universities: Evidence from randomized trials. ITHAKA 2012. [CrossRef]

22. Hilton, J., III; Gaudet, D.; Clark, P.; Robinson, T.J.; Wiley, D. The adoption of open education resources by one community college math department. Int. Rev. Res. Open Distrib. Learn. 2013, 14. [CrossRef]

23. Wiley, D.; Hilton, J.; Ellington, S.; Hall, T. A preliminary examination of the cost savings and learning impacts of using open textbooks in middle and high school science classes. Int. Rev. Open Distrib. Learn. 2012, 13. Available online: http://www.irrodl.org/index.php/irrodl/article/view/1153/2256 (accessed on 1 June 2019).

24. Morales, R.; Baker, A. Secondary Students' Perceptions of Open Science Textbooks. J. Int. Media Educ. 2018, 4, 1-9. Available online: https://www.researchgate.net/publication/322730070_Secondary_Students \T1〉 textquoteright_Perceptions_of_Open_Science_Textbooks (accessed on 1 June 2019). [CrossRef]

25. Allen, E.; Seaman, J. Opening the Textbook: Educational Resources in U.S. Higher Education. Babson Surv. Res. Group 2016, 2015-2016. Available online: https://www.onlinelearningsurvey.com/reports/ openingthetextbook2016.pdf (accessed on 1 June 2019).

26. Hurt, L. Student Perceptions and Understanding of Open Education Resources. Unpublished Master's Thesis, De Montfort University, Leicester, UK, January 2013. 
27. Onaifo, D. Alternate Academy: Investigating the Use of Open Educational Resources by Students at the University of Lagos in Nigeria. Unpublished Ph.D. Thesis, The University of Western Ontario, London, UK, 2016. Available online: https://oerknowledgecloud.org/sites/oerknowledgecloud.org/files/Investigating\% 20the \%20Use \%20of\%20Open\%20Educational\%20Resources\%20by\%20Students\%20in\%20Nigeria.pdf (accessed on 1 June 2019).

28. Gruszczynska, A. HEA/JISC Open Educational Resources Case Study: Pedagogical Development from Oer Practice, Open Educational Resources as A Pedagogical Practice That Enhances Student Satisfaction; The Higher Education Academy, Sheffield Hallam University: Heslington, UK, 2012; Available online: https://www.heacademy.ac. uk/system/files/oer_cs_anna_gruszczynska_open_educational_resources.pdf (accessed on 1 June 2019).

29. Kurelovic, E.K. Advantages and Limitations of Usage of Open Educational Resources in Small Countries. Int. J. Res. Educ. Sci. 2016, 2, 136-142. Available online: https://oerknowledgecloud.org/sites/oerknowledgecloud. org/files/5000123134-5000259500-1-PB.pdf (accessed on 1 June 2019). [CrossRef]

30. University of the People n.d. Lack of Awareness is the Biggest Obstacle for Open Educational Resources. Available online: https://www.uopeople.edu/blog/lack-of-awareness-is-the-biggest-obstacle-foropen-educational-resources/ (accessed on 1 June 2019).

(C) 2019 by the authors. Licensee MDPI, Basel, Switzerland. This article is an open access article distributed under the terms and conditions of the Creative Commons Attribution (CC BY) license (http://creativecommons.org/licenses/by/4.0/). 